\title{
Expansion of Preventive Dental Service Coverage for Certain Medicaid Beneficiaries in Texas: A Call for Dental Policy Effectiveness Action
}

\author{
Naiya Patel *(D) and Neel Patel \\ School of Public Health and Information Sciences, University of Louisville, Louisville, KY 40202, USA; \\ neelppatel696@gmail.com \\ * Correspondence: naiya.patel@louisville.edu
}

check for updates

Citation: Patel, N.; Patel, N.

Expansion of Preventive Dental

Service Coverage for Certain

Medicaid Beneficiaries in Texas: A

Call for Dental Policy Effectiveness

Action. Oral 2021, 1, 261-271.

https://doi.org/10.3390/oral1030025

Academic Editor: Rachel Tham

Received: 4 August 2021

Accepted: 30 August 2021

Published: 3 September 2021

Publisher's Note: MDPI stays neutral with regard to jurisdictional claims in published maps and institutional affiliations.

\begin{abstract}
Background: It is vital to provide evidence-based research documentation to guide policy decision-making. There is a limited number of studies that participate in dental policy evidence-based research. Case Description: Texas is one of the states with limited dental service coverage for its Medicaid Beneficiaries. The recent senate bill 87R 1152 proposes expansion of dental preventive service to disability status Medicaid Beneficiaries. It is vital to understand how effective the extensive dental service under Medicaid coverage is through evidence-based research. True causal analysis of such public policies by utilizing observational data is only feasible through limited identification strategies. The current paper identifies that. Practical Implication: Through the identified research plan and conceptual framework, it can be established if extensive Medicaid dental service coverages effectively prevent dental disease burden in Texas.
\end{abstract}

Keywords: dental policy; preventive dental services; dental public health; Medicaid expansion

\section{Introduction}

The five dimensions of access are availability, accessibility, accommodation, affordability, and acceptability [1]. Availability is a relationship between facilities, healthcare supplies, and patient's healthcare needs volume [1]. Accessibility defines the distance between patient and provider, meaning travel time and transportation factors to seek healthcare service [1]. Accommodation establishes the relationship between the delivery system, the structure of healthcare facilities set up to accept patients, and the patient's ability to accept it [1]. It includes appointment timings, hours of operations, mobile services, walk-in facilities, etc. [1]. Affordability is the relationship between the healthcare provider's charges for the services they provide and the patient's income ability to pay for the services they might seek from those providers [1]. Finally, acceptability means both the patient's and provider's tendency to accept the attributes of each other [1], meaning patients might be willing to go to certain types of facilities, neighborhood, as well as their tendency to accept the provider's gender or race. Likewise, the providers might not be willing to accept certain patients holding a kind of insurance coverage they do not accept [1]. It has also been determined that if a problem exists among any dimensions of access, it could influence patients and healthcare delivery systems that are measurable in three ways [1]. First, is lowered utilization of services, lower patient satisfaction of the healthcare services, and change in provider practices such as reduced patient time [1].

Access to healthcare is defined as "the timely use of personal health services to achieve the best health outcomes" [2]. The model of access to personal healthcare services is depicted in Figure 1 [2]. It is clear from the model that accesses barriers can be divided into three domains for personal care: (1) Structural, (2) Financial, and (3) Personal, while the outcome indicators are equity of services and overall health status. Utilization of healthcare services, such as underuse/overuse, serves as an indicator or barrier to access to needed 
healthcare [2]. The model establishes in Figure 1 that access to needed healthcare impacts an individual's health and wellbeing [2]. Another indicator of access to healthcare is health outcomes, which could be used as a complementary indicator of healthcare services' utilization [2]; indeed, a person might receive the healthcare service they seek. However, other factors such as personal characteristics and vulnerabilities might not help achieve overall health and wellbeing relevant to services they receive [2]. Hence, it is essential to utilize two access indicators as complementary, i.e., health outcomes and utilization of services [2]. Access to healthcare barriers is significantly impacted by insurance coverage, as barriers to access inculcate its financial domain.

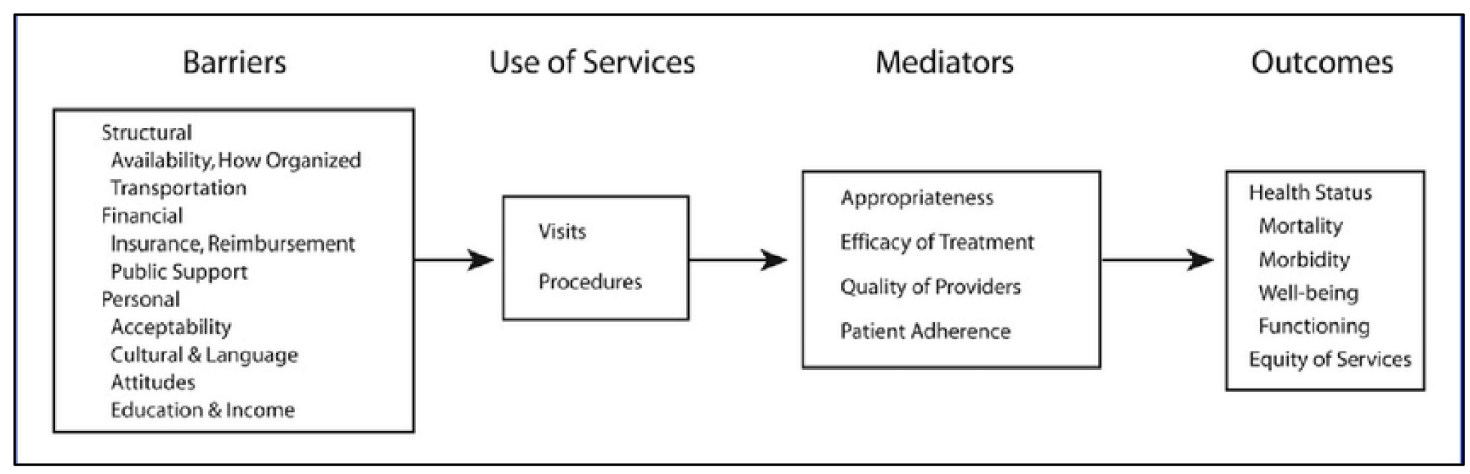

Figure 1. Model of access to personal health care services [2].

The government of any country might be keen to improve their population's health, as better health reduces overall healthcare spending of a country per capita, increasing the size of a population due to the demographic shift of the aging population for longer life. Better health means more productive days and better earnings and employment choices [3]. In the absence of public policy, uninsured individuals have been reimbursed through state uncompensated pools [4], meaning the state budget covers healthcare for the uninsured. The financial barriers for needed access to care are overcome through public policies such as Medicaid expansion, Affordable Care Act Legislation [4], and other generous health insurance plans [5]. The current paper proposes an evidence-based identification strategy for future studies that aim to identify policy effectiveness in the states already implementing Medicaid expansion of dental services. The paper proposes research methods that can inform the senate bill in Texas as evidence for anticipated benefits. For a bill to transition into a law/policy, sufficient evidence in the form of research is vital. Hence, the current paper's aims are:

1. To identify factors associated with poor oral health: problem analysis.

2. To determine the role of Medicaid expansion for preventive dental service coverage: solution analysis.

3. To identify critics of public insurance policies such as Medicaid expansion of preventive dental services and describe their role in influencing the process of transitioning from bill to policy.

4. To propose an evidence-based theory framework and research methodology for future research.

5. To identify key outcome variables, independent variables, covariates, identification strategy for causal analysis of policy effectiveness, and potential validity threats.

\section{Problem Analysis: Oral Health and Preventive Dental Services}

Oral health problems lead to several adverse consequences to the nation's Medicaid and the general population [6]. Factors such as inability to keep a job, adverse pregnancy events, elevated risk of general chronic conditions, inflammatory diseases, bodily nutritional imbalance, and oral cancer are impacted by poor oral health [6,7]. Medicaid beneficiaries, compared to their privately insured counterparts, are more likely to face access to healthcare barriers for preventive dental care services, bear the disproportional 
burden of dental disease, and as a result, have poor oral health outcomes [6,7]. Adults with disabilities of any degree are more prone to dental disease and its severe consequences [7]. Higher costs for dental care services and limited dental insurance coverage are significant barriers to access to dental care [8]. Poor oral health leads to high-cost acute care utilization that could be prevented through preventive dental service utilization [7]. About 30\% of the U.S. Medicaid beneficiaries and $40 \%$ of the uninsured population lead to about USD 2.7 billion in dental-related hospital emergency department visits over the past three years [7]. Several barriers to access to dental care and its utilization have been identified [7]. It includes inadequate dental coverage, insufficient provider availability, and individual level barriers such as lack of dental benefit and oral health literacy, lack of referral to oral care through primary providers, and perspective as the least priority in terms of overall healthcare [7]. As depicted in Figure 2, states with Medicaid adult dental benefits have three types of coverage: Limited, Emergency-only, and Extensive [7]. While the other two types cover preventive dental services in Medicaid, the Emergency-only type does not cover preventive dental service costs for enrolled Medicaid beneficiaries [7].

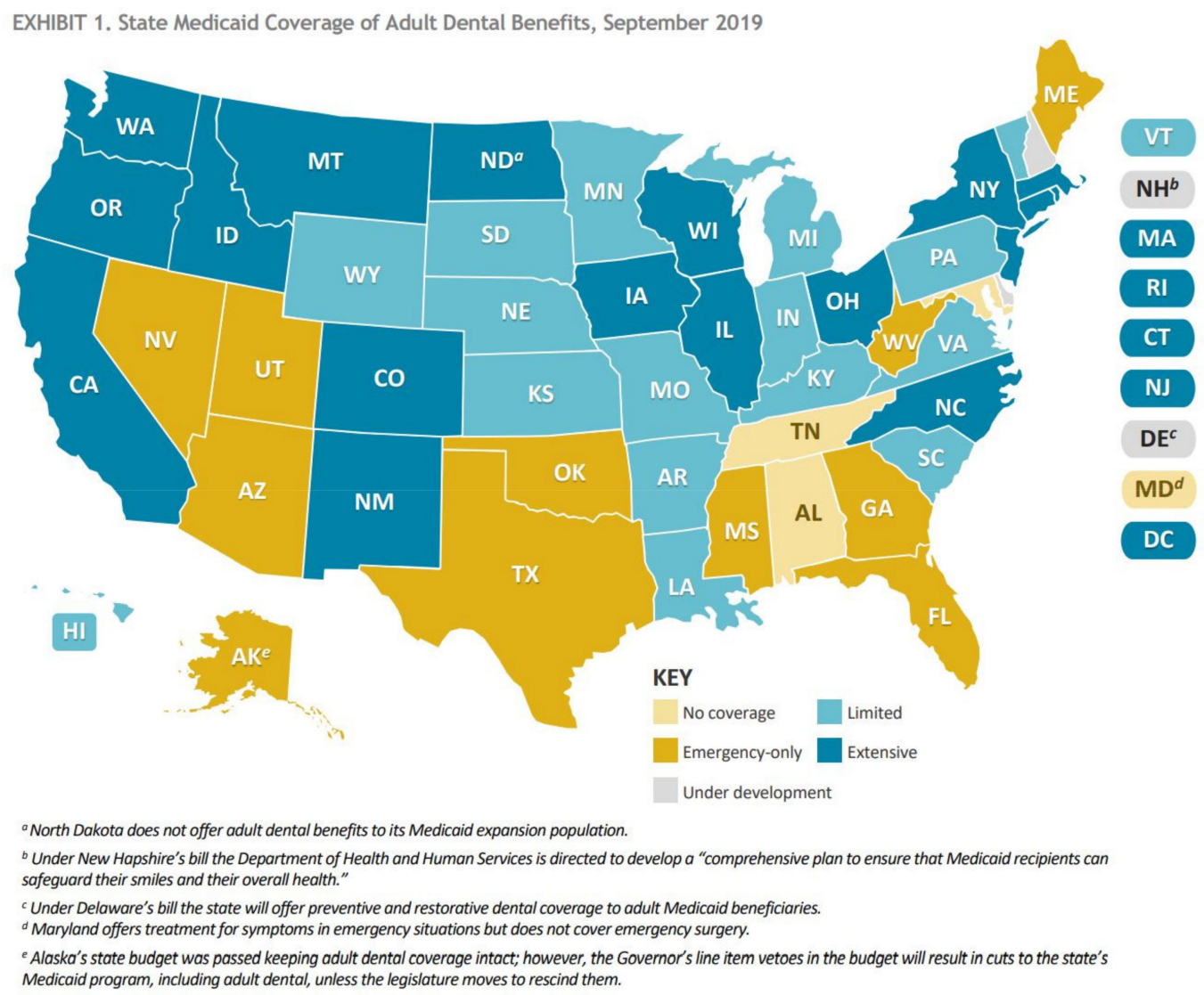

Figure 2. States Medicaid coverage for dental benefits [7].

The Texas senate bill filed, if passed, would allow reimbursement for preventive dental health services for certain Medicaid covered adults in the Texas Medicaid program, especially those adults with disabilities. The text of the original bill can be found on https: / / capitol.texas.gov/BillLookup/Text.aspx?LegSess=87R\&Bill=SB1152 (accessed on 1 August 2021).

\section{Solution Analysis: Public Dental Insurance Coverage and Access to Dental Care}

Public policies and legislation such as the Affordable Care Act Medicaid Expansion have been positively associated with improved access to care and other benefits [9]. Medicaid Expansion has reduced the proportion of uninsured populations in the United States 
faster than the non-expansion states [9]. Medicaid expansion has helped reduce the coverage disparity among vulnerable racial and ethnic groups and other vulnerable groups, such as non-gender confirming identities, rural areas, and newly diagnosed cancer patients $[9,10]$. Studies have also established that Medicaid expansion has helped improve a wide range of healthcare access and utilization of needed healthcare services among lowincome and vulnerable populations $[9,11]$. Improved access to care has also helped improve the diagnosis of diseases among chronic conditions $[9,11]$. Compared to non-expansion states, expansion states have observed increased access to medication and services such as mental and behavioral health $[9,11]$. Improvement in access and affordability to care due to Medicaid expansion has reduced existing disparity among socioeconomically vulnerable populations [9]. Reduced emergency department visits and length of stay in hospitals have been associated with Medicaid expansion in certain states [4,9,11]. Medicaid expansion has also declined uncompensated care costs for providers and improved state revenues, personal financial security, and budget savings, indicating economic growth $[9,11]$.

Assessing the impact on health due to lack of insurance coverage is a complex effect to measure as it involves lagged effects and confounding situations [11]. The effect of insurance coverage varies among populations and types of plans [11]. However, a public policy such as health insurance coverage seems to be a particular case compared to other types of insurance due to the absence of push by the federal government [11]. Publicly subsidized health insurance can redistribute resources to socioeconomically vulnerable groups and help achieve public health goals [11]. Several chronic conditions and risky health behaviors can be prevented through preventive services [12]. Improved coverage through Medicaid for preventive services such as screening, vaccination, smoking cessation, and other programs have improved overall health, reduced high-cost care utilization, and help manage conditions at the primary stage [12]. Medicaid coverage has also proven to maintain continuity of care and primary or usual source of care leading to addressing unmet medical needs [12].

Access to preventive dental care services through Medicaid coverage can help reduce the overall acute care cost burden associated with emergency department use due to dental origin problems [7]. Due to limited incentives to dental insurers, the burden of out-of-pocket cost for emergency department use due to dental problems is shifted to the patient [13]. Therefore, Medicaid covers the cost of emergency department visits due to dental problems and bears the burden of avoidable acute care costs, which could be solved by covering dental preventive care services [13]. Thus, coverage of preventive healthcare services helps reduce the healthcare cost burden and improve overall health outcomes [13]. Furthermore, adults with low-income are more prone to decline the oral health service utilization if Medicaid does not cover dental services [14]. Hence, problem and solution analysis show that preventive services such as preventive dental healthcare services through Medicaid can help the government improve access to care for its population. Furthermore, Medicaid coverage for preventive care helps solve the financial barrier to access to care for its beneficiary, although it is the first to face financing problem due to state budgetary constraints [13].

Improved access, healthcare service utilization, and reduced overall healthcare cost could be achieved by cost-sharing inculcated in insurance policies, although mixed effects are reported [15]. Participation in Accountable Care Organizations (ACOs) has also proven to be access effective in reducing avoidable emergency department (E.D.) visits and improvement in primary care services delivery to the population [16]. Patient-centered medical homes have also effectively improved access, cost, and healthcare quality needed by the people [17]. Finally, triple aims is one of the goals that could help improve healthcare utilization and services [18].

\subsection{Critics of Legislation-Public Insurance Policies}

Some critics of Medicaid expansion consider the existing policy uncertain on the federal budget and causing decreased state flexibility [10]. Thus, coverage of additional 
services within Medicaid might not seem a priority to its critics. The critics further emphasize that introducing grants, caps, and fixed per person spending would help reduce the federal Medicaid healthcare spending by $26 \%$ [10]. It is believed that public policy such as Medicaid provides low reimbursement to providers due to state and federal budget constraints. For the same reason, providers do not want to accept Medicaid beneficiaries [19]. Critics have cited several studies to establish that Medicaid beneficiaries are more likely to die early, have more extended hospital stays, have a lower quality of care than their counterparts, and carry the highest risk of death [19]. Critics have also cited studies about the quality of care Medicaid beneficiaries that tend to suffer more adverse events than their counterparts after controlling for patient characteristics [19]. Hence, given the perceived evidence, taxpayers whose money partially funds such public policies might oppose further funding through additional service coverage. It is also assumed that to support and sustain state deficits of public policy such as Medicaid [20], and the beneficiaries would indirectly pressure the government to redirect taxpayer dollars to support sustainability [19]. Since the highest proportion of state budgeting is occupied by Medicaid spending, it constrains states to allocate limited resources on other welfare activities such as primary education [20]. So additional service coverage might act as a burden to already limited resources for the state. The presence of Medicaid patient cap among doctors has been the greatest concern as it limits the ability of a patient to seek timely care [19].

Similarly to public insurance policies, health reform seems to affect four groups of people in the United States [21]. Group 1: Medicaid or CHIP (Children's Health Insurance Plan) or Uninsured, Group 2: Individual and Small Group Insurance purchasers such as firms with less than 50 employees, Group 3: Midsize and Large employers, and Group 4: Medicare [21]. The reason behind determining the groups of people affected by such policies is to establish how implementation and acceptance of such policies might occur? [21] The prominent critics of public policy are the providers like doctors, specialists of certain services, some State's Governors [21,22], taxpayers [21] who do not seek Medicaid benefits, and certain political parties [21] due to the above reasons. However, one study reflects that Medicaid expansion is not associated with increased state funds, nor a reduction in spending on education and other welfare programs [23].

As depicted in Table 1, the key identified stakeholders that either serve as critics and or influencers are Dental and Primary care providers, Taxpayers of the state, the Governor of the State, political parties ruling in the state, the legislation, and coverage beneficiaries. The key critics of the dental preventive service coverage under Medicaid with higher opposition are Texas taxpayers, Governor, and political parties with opposing political perspectives and motives $[8,24,25]$, and also described in the above paragraph and table, is the major reason behind opposition. The level of opposition to the bill depends on the stakeholder's level of influence, the bill's impact on them if it passes, and interest level.

Table 1. Key critics and influencers for determining opposition of legislation regarding preventive dental service coverage in Medicaid.

\begin{tabular}{|c|c|c|c|c|c|}
\hline Stakeholders & $\begin{array}{l}\text { Healthcare Physicians and } \\
\text { Dentists }\end{array}$ & Taxpayers of Texas & Texas State Governor & $\begin{array}{c}\text { Texas Beneficiaries of } \\
\text { the Policy }\end{array}$ & Political Parties \\
\hline Role & $\begin{array}{l}\text { Provide needed healthcare } \\
\text { service [8] }\end{array}$ & $\begin{array}{l}\text { Pay taxes as } \\
\text { prescribed, which } \\
\text { in return funds } \\
\text { public programs }\end{array}$ & $\begin{array}{l}\text { Educate the population, } \\
\text { serve the healthcare } \\
\text { needs of population, } \\
\text { improve healthcare } \\
\text { provision, support } \\
\text { policies beneficial to } \\
\text { state, authorize needed } \\
\text { actions for state benefit }\end{array}$ & Seek and receive care [8] & $\begin{array}{l}\text { Provide vote, lobby, or } \\
\text { influence key players } \\
\text { for passing a bill in the } \\
\text { context of policy }\end{array}$ \\
\hline Level of Interest & $\begin{array}{l}\text { Moderate } \\
\text { As depends on direction of } \\
\text { reimbursement amounts }\end{array}$ & $\begin{array}{c}\text { Moderate } \\
\text { Depending on the } \\
\text { movement of the } \\
\text { bill }\end{array}$ & $\begin{array}{c}\text { High } \\
\text { As impacts state budget } \\
\text { deficits and reallocation } \\
\text { or resources }\end{array}$ & $\begin{array}{l}\text { High } \\
\text { Because they receive } \\
\text { access to care }\end{array}$ & $\begin{array}{l}\text { High } \\
{[25]}\end{array}$ \\
\hline
\end{tabular}


Table 1. Cont.

\begin{tabular}{|c|c|c|c|c|c|}
\hline Stakeholders & $\begin{array}{l}\text { Healthcare Physicians and } \\
\text { Dentists }\end{array}$ & Taxpayers of Texas & Texas State Governor & $\begin{array}{c}\text { Texas Beneficiaries of } \\
\text { the Policy }\end{array}$ & Political Parties \\
\hline Level of Influence & $\begin{array}{c}\text { Moderate } \\
\text { As depends on the level of } \\
\text { policy development } \\
\text { involvement allowed by } \\
\text { legislatures and market } \\
\text { concentration }\end{array}$ & $\begin{array}{l}\text { Moderate } \\
\text { No influence other } \\
\text { than voting, } \\
\text { campaigning } \\
\text { against the bill }\end{array}$ & High & $\begin{array}{l}\text { Moderate } \\
\text { No influence other than } \\
\text { voting or campaigning } \\
\text { about rights to the } \\
\text { extremes }\end{array}$ & $\begin{array}{l}\text { High } \\
\text { Help support or oppose } \\
\text { the policy in legislation } \\
\text { depending on the role }\end{array}$ \\
\hline Perspective/Need & $\begin{array}{l}\text { Provide } \\
\text { quality/effective/evidence- } \\
\text { based care in return of } \\
\text { competitive timely } \\
\text { reimbursement }\end{array}$ & $\begin{array}{c}\text { Receive quality } \\
\text { services funded by } \\
\text { state government } \\
\text { such as primary } \\
\text { education, better } \\
\text { transportation and } \\
\text { other state } \\
\text { community } \\
\text { priorities }\end{array}$ & $\begin{array}{l}\text { To serve the community } \\
\text { for their wellbeing and } \\
\text { safety }\end{array}$ & $\begin{array}{l}\text { Overall wellbeing, } \\
\text { continuity of care and } \\
\text { improved productivity }\end{array}$ & $\begin{array}{l}\text { Political perspective is } \\
\text { satisfied or provide } \\
\text { majority through voting } \\
\text { benefiting their } \\
\text { respective parties }\end{array}$ \\
\hline $\begin{array}{l}\text { Level of impact of } \\
\text { policy on them }\end{array}$ & $\begin{array}{c}\text { Moderate } \\
\text { Only high in cases when } \\
\text { increased amount of } \\
\text { reimbursement }\end{array}$ & $\begin{array}{l}\text { Low } \\
\text { The bill does not } \\
\text { impact them } \\
\text { directly }\end{array}$ & $\begin{array}{c}\text { High } \\
\text { If bill passes, the state } \\
\text { budget will be impacted } \\
\text { [25] }\end{array}$ & $\begin{array}{l}\text { High } \\
\text { Better access to care }\end{array}$ & $\begin{array}{l}\text { Moderate } \\
\text { If the bill passes, no } \\
\text { direct impact }\end{array}$ \\
\hline $\begin{array}{l}\text { Level of } \\
\text { friction/opposition }\end{array}$ & $\begin{array}{l}\text { Low } \\
\text { Agree that access to } \\
\text { preventive dental care } \\
\text { improves overall health [8] }\end{array}$ & $\begin{array}{c}\text { High } \\
\text { As per past } \\
\text { fraudulent incident } \\
\text { among Medicaid } \\
\text { Dental } \\
\text { Beneficiaries, they } \\
\text { might perceive the } \\
\text { bill to be a } \\
\text { facilitator of more } \\
\text { frauds [24] }\end{array}$ & $\begin{array}{l}\text { High } \\
\text { As the favor towards } \\
\text { passing the bill might } \\
\text { have its own } \\
\text { consequences. The fact } \\
\text { that the existing } \\
\text { administration since } \\
\text { past years have not } \\
\text { passed it for same } \\
\text { underlying reasons }\end{array}$ & $\begin{array}{l}\text { Low } \\
\text { As need improved } \\
\text { access to dental care } \\
\text { services [8] }\end{array}$ & $\begin{array}{l}\text { High } \\
\text { By opposition party }\end{array}$ \\
\hline
\end{tabular}

\subsection{Measuring Policy Effects-Empirical Literature}

The criteria for identifying policy analysis are relevance, validity, and reasonableness [26]. As depicted in Figure 3, the health services research model is utilized in policy analysis depending on the criteria we want to evaluate [26]. The conceptual framework proposed by health services research inculcates system, institution, and patient/individual level constructs that help determine the relationship and define a problem [26]. Hence, it is established that the Andersen and Aday model for health services research is a conceptual model utilized extensively for evaluating policy effects. The literature so far has measured several outcomes for the Medicaid Expansion Policy, such as measures of access to care, health and quality of care, hospital financial performance, and cost of care [27].

Access to care (affordability) measures utilized to study Policy effect consist of the following factors for the research design [28-32]:

Outcome variable: Studies in the literature have utilized several factors as outcome variables such as the type of insurance coverage [28,30,33], the percentage uninsured [29,31], access to and use of care [30], as well as out-of-pocket medical spending [30].

Predictor variable: Studies used demographics such as age, female, race, foreign-born, and U.S. citizenship [28-33]. Another group of covariates utilized is a family structure such as marital status and number of children in a household $[28,30,33]$. The economical group of covariates comprised primary occupation, education, employment status, and household income $[28,30]$. Types of insurance exchanges, anyone in a family with a disability [30] also serve as covariates to control empirical studies [28].

Comparison groups: The literature has utilized several comparison groups, such as expansion states versus non-expansion states for Medicaid [28,31,32], and expansion counties versus non-expansion counties $[30,33]$.

Research design: Difference in difference model [28,30,33], and trends analysis pre and post-expansion [32]. 


\begin{tabular}{|c|c|}
\hline Dimensions & Criteria \\
\hline \multicolumn{2}{|l|}{ Effectiveness } \\
\hline Population perspective & Maximize population health. \\
\hline Clinical perspective & $\begin{array}{l}\text { Maximize actual health benefits } \\
\text { of healthcare services compared } \\
\text { to potential benefits. }\end{array}$ \\
\hline \multicolumn{2}{|l|}{ Efficiency } \\
\hline Allocative efficiency & $\begin{array}{l}\text { Ensure a mix of healthcare services } \\
\text { that maximizes a combination of } \\
\text { health outcomes and consumer } \\
\text { satisfaction at least cost. }\end{array}$ \\
\hline Production efficiency & $\begin{array}{l}\text { Produce healthcare services that } \\
\text { maximize output at least cost. }\end{array}$ \\
\hline \multicolumn{2}{|l|}{ Equity } \\
\hline Distributive justice & $\begin{array}{l}\text { Maximize freedom of choice of } \\
\text { plans/providers/services, cost- } \\
\text { effectiveness, similar treatment. }\end{array}$ \\
\hline Social justice & $\begin{array}{l}\text { Maximize common good. Meet } \\
\text { basic needs. }\end{array}$ \\
\hline Deliberative justice & $\begin{array}{l}\text { Maximize participation of affected } \\
\text { parties. }\end{array}$ \\
\hline
\end{tabular}

Figure 3. Dimensions and criteria to evaluate health policy utilizing health services' research model [26].

Other studies that measure utilization of health services, an indicator of access to health care to study Policy effect consist of the following factors in their research design [34-39]:

Outcome variable: Several outcome variables served as a measurement of similar types of research studies such as community health center visits rates among the uninsured, Medicaid-insured, and commercially insured [34,36] patients treated by particular payer type, charity care, and bad debt costs, hospital discharges, and outpatient visits [35], listing rate of a heart transplant [37], and E.D. visit volume/E.D. Hospitalization rate [39]. One study measured four outcomes: the proportion of patients without insurance coverage, patients with Medicaid and private coverage, the unique number of patients seen, and the quality of care received [38].

Predictor variable: Household income, age [36,37], sex [36-38], race [36,37], rural or urban residence, minimum wage, unemployment rates [34], hospital and market variables such as [35]: "total number of staffed and set-up hospital beds, hospital provision of substance abuse services, and hospital provision of burn services, number of hospital beds per 1000 residents in a county, percent of hospital beds in a county that was public, the Herfindahl-Hirschman Index of hospital competition (based on hospital discharges), managed care patient share, the percent of the county population that was African American, the percent of the county population that was Hispanic, and the percent of the county population that was low income". HIV risk factors [36] and community health center characteristics [38] also served as covariates in some studies.

Comparison Group: Expansion versus non-expansion state [34,38], expansion versus non-expansion county [35,39], Medicare coverage versus other types [36], and early versus non-adopter of ACA expansion [37].

Research Design: Poisson Regression Model [34], Difference in Difference [35,38] multinomial logistic regression [36], stratified linear model [37], Ordinary Least Square Regression [39].

Validity: Sensitivity analysis $[35,38]$ is a way to study the robustness of the study results. However, external validity threats exist such as the unrepresentative sample [36], data limitation leading to an underestimation of effect $[37,38]$. 
3.3. Research Methods Proposal-Studying the Effects of the Filed Senate Bill 87(R) 1152 in Texas-Research Approach to Provide Evidence-Based Effect for the Bill Vote

The following identification strategy can help support the bill under consideration in Texas. First, the identification strategy helps identify the true causal effect of the potential comprehensive/extensive Medicaid dental services coverage the current bill proposes in Texas.

Outcome variable: As established in the empirical literature, access to and use of care and out-of-pocket spending can be an outcome variable for the study. Preventive dental service-specific studies have utilized preventive dental visits to the dentist (Griffin et al., 2014) and unmet dental needs in the past 12 months as outcome variables [40].

Covariates: In the literature, several variables serve as covariates for similar kind of studies that include Income-based Medicaid eligibility indicator, type of insurance coverage, and family characteristics such as average family income, number of family members [41]. Further covariates such as health status, age, race, and education level are utilized in past literature [41]. Other covariates such as gender, citizenship status, marital status, number of children in household, primary occupation, employment status, anyone in the family with a disability, types of dental insurance exchanges present in the state of New Mexico, rural or urban residence, market variable such as number of dental clinics and number of dentists to population ratio, the reimbursement rate for the preventive service, dental health literacy indicator, fear for dentists and dental service, distance to nearest dental clinic, an optimal level of water fluoridation in community, risky eating habits, dental clinic working hours, wait time, and community health characteristics. These covariates have been identified as barriers to dental care, as mentioned in the problem analysis, so it is vital to account for them to understand the true effects of policy.

Conceptual Model: As mentioned in the empirical literature above, Andersen and Aday's Model serves as an excellent conceptual model to inform policy effectiveness. However, the definition of each model's constructs is partially dependent on the context of the study, data limitation, and subjective perspectives. At the same time, the remaining definition knowledge comes from the empirical literature.

Comparison group: Literature has utilized non-expansion states more preferably neighboring states without implementing policy or intervention [40-42]. If treatment and control groups are not comparable, the presence of selection bias will mask off the true effect, and the estimates of the effect will be biased [43]. The selection bias exists if the treatment and control groups differ more than just the treatment intervention aspect. Utilizing New Mexico as a comparison group, given it shares its border with Texas, can serve as an appropriate control group. Treatment (bill) differs in terms of preventive dental service as depicted in Figure 2. Texas, currently with only emergency dental services covered, serves as a good comparison group. Other neighboring states either cover the preventive service with limited services category or extensively cover dental services that include preventive dental care. Therefore, they do not serve as a good comparison or counterfactual scenario and threaten internal validity [43].

\subsection{Limitations}

The validity threat and its presence depend on data limitation, research identification strategy, conceptual model construct definition, and research context.

Internal validity threat to the proposed study: In general, the literature mentions underestimating or overestimating the true effect as the most significant internal validity threat. However, depending on data limitations, construct definition and data collection tool errors if present, omitted variable bias presence, and mismeasurement error might be some of the internal validity threats to existing proposed research [43].

External validity threat to the proposed study: The data limitation would limit the sample variables and depend on the observables, and might not generalize the effect at the population level [43]. However, some potential external validity threats could be policy effects that might not remain the same if the outcome is changed to some dental-related 
emergency department visits. For example, if the setting from dental clinics to federally funded dental clinics is changed, the possibility of interaction with the setting might pose an external validity threat [43].

\section{Conclusions}

The paper describes the factors affecting access to healthcare, indicators of access to health, and governmental interest to improve access to healthcare for its citizen. It also describes contextual access to dental care barriers, the magnitude of the oral health problem, and factors affecting preventive dental care services access. The policy analysis section explains how Medicaid expansion, one of the public policies, helps improve access to healthcare and reduce the overall cost of dental care burden for a government. The role of public policies in improving access to general preventive and dental services is also explained. Additionally, critics of public policies in general and the context of dental preventive service bills are described in the paper. The critics will play a vital role in influencing the potential Texas bill, so a critical analysis matrix is vital in identifying the feasibility of the bill. Finally, the empirical literature measuring policy effects such as Medicaid service expansion is described to determine the types of variables and threats they face. The paper then describes how the health services research literature serves as a foundation for determining potential dental policy study variables, conceptual models, and threats to validity to help identify the true causal effect of such an extensive dental service policy. Hence, the paper provides the foundation for future research to identify similar policy expansion effects and help guide decision-making of passing the Texas bill into policy implementation.

Implications for such research mean increased patient volume for dental practices accepting Medicaid dental beneficiaries, who may improve preventive oral care to those qualified under the new bill if passed. Finally, better access to preventive dental care services means improved population dental health through Texas dental practices.

Author Contributions: Conceptualization, N.P. (Naiya Patel); methodology, N.P. (Naiya Patel); software, N.P. (Neel Patel); resources, N.P. (Neel Patel); writing—original draft preparation, N.P. (Naiya Patel); writing—review and editing, N.P. (Naiya Patel), N.P. (Neel Patel); visualization, N.P. (Neel Patel). Both authors have read and agreed to the published version of the manuscript.

Funding: This research received no external funding.

Institutional Review Board Statement: Not applicable for studies not involving humans or animals. Informed Consent Statement: Not applicable.

Conflicts of Interest: The authors declare no conflict of interest.

\section{References}

1. Penchansky, R.; Thomas, J.W. The Concept of Access. Med. Care 1981, 19, 127-140. [CrossRef] [PubMed]

2. Academies. Committee on Monitoring Access to Personal Health Care Services I of M. A model for monitoring access. In Access to Health Care in America; Academies: Cambridge, MA, USA, 1993; pp. 31-45.

3. Congressional Budget Office. Raising the Excise Tax on Cigarettes: Effects on Health and the Federal Budget; Executive Summary; Congressional Budget Office: Washington, DC, WA, USA, 2012.

4. Stryjewski, T.P.; Zhang, F.; Eliott, D.; Wharam, J.F. Effect of Massachusetts Health Reform on Chronic Disease Outcomes. Health. Serv. Res. 2014, 49 (Suppl. S2), 2086-2103. [CrossRef]

5. Manning, W.G.; Newhouse, J.P.; Duan, N.; Keeler, E.B.; Leibowitz, A.; Marquis, M.S. Health insurance and the demand for medical care: Evidence from a randomized experiment. Am. Econ. Rev. 1987, 77, 251-277. [PubMed]

6. Mcginn-Shapiro, M. Medicaid Coverage of Adult Dental Services; The National Academy for State Health Policy: Washington, DC, WA, USA, 2008.

7. Medicaid Adult Dental Benefits: An Overview. 2019. Available online: https://www.chcs.org/resource/medicaid-adult-dentalbenefits-overview/ (accessed on 1 August 2021).

8. DentaQuest. Reversible Decay: Oral Health Is A Public Health Problem We Can Solve. 2019. Available online: https: / / dentaquest. $\mathrm{com} / \mathrm{pdfs} /$ reports/reversible-decay.pdf/ (accessed on 1 August 2021). 
9. Antonisse, L.; Garfield, R.; Rudowitz, R.; Artiga, S. The Effects of Medicaid Expansion under the ACA: Updated Findings from a Literature Review; Kaiser Family Foundation: Washington, DC, USA, 2018. Available online: https://files.kff.org/attachment/ Issue-Brief-The-Effects-of-Medicaid-Expansion-Under-the-ACA-Updated-Findings-from-a-Literature-Review (accessed on 1 August 2021).

10. Sommers, B.D.; Grabowski, D.C. What Is Medicaid? More Than Meets the Eye. JAMA 2017, 318, 695. [CrossRef]

11. Sommers, B.D.; Gawande, A.A.; Baicker, K. Health Insurance Coverage and Health-What the Recent Evidence Tells Us. New Engl. J. Med. 2017, 377, 586-593. [CrossRef]

12. Ku, L.; Paradise, J.; Thompson, V. Data Note: Medicaid's Role in Providing Access to Preventive Care for Adults; Kaiser Family Foundation: Washington, DC, WA, USA, 2017. Available online: https://www.kff.org/medicaid/issue-brief/data-note-medicaids-rolein-providing-access-to-preventive-care-for-adults/ (accessed on 1 August 2021).

13. Huang, S.S. Should Medicaid include adult coverage for preventive dental procedures? What evidence is needed? J. Am. Dent. Assoc. 2020, 151, 607-613. [CrossRef]

14. Chazin, S.; Guerra, V.; McMohan, S. Strategies C for H.C. Strategies to Improve Dental Benefits for the Medicaid Expansion Population; Center for Healthcare Strategies Inc.: Hamilton, NJ, USA, 2014. Available online: https:/ / www.chcs.org/resource/strategies-toimprove-dental-benefits-for-the-medicaid-expansion-population/ (accessed on 1 August 2021).

15. Remler, D.K.; Greene, J. Cost-Sharing: A Blunt Instrument. Annu. Rev. Public Heal. 2009, 30, 293-311. [CrossRef] [PubMed]

16. Hsu, J.; Price, M.; Vogeli, C.; Brand, R.; Chernew, M.E.; Chaguturu, S.K.; Weil, E.; Ferris, T.G. Bending the Spending Curve By Altering Care Delivery Patterns: The Role Of Care Management Within A Pioneer ACO. Heal. Aff. 2017, 36, 876-884. [CrossRef]

17. Peikes, D.; Zutshi, A.; Genevro, J.L.; Parchman, M.L.; Meyers, D.S. Early evaluations of the medical home: Building on a promising start. Am. J. Manag. Care 2012, 18, 105.

18. Whittington, J.W.; Nolan, K.; Lewis, N.; Torres, T. Pursuing the Triple Aim: The First 7 Years. Milbank Q. 2015, 93, 263-300. [CrossRef]

19. Gottlieb, S. Medicaid Is Worse Than No Coverage at All. Wall Str. J 2011. Available online: https://www.wsj.com/articles/SB100 01424052748704758904576188280858303612 (accessed on 1 August 2021).

20. Miller, D. Growing Medicaid Budgets Squeezing Out Other Priorities; CSG: Lexington, KY, USA, 2012. Available online: http: // knowledgecenter.csg.org/kc/content/growing-medicaid-budgets-squeezing-out-other-priorities (accessed on 1 August 2021).

21. Newhouse, J.P. Assessing Health Reform's Impact on Four Key Groups of Americans. Heal. Aff. 2010, 29, 1714-1724. [CrossRef] [PubMed]

22. Sommers, B.D.; Epstein, A.M. U.S. Governors and the Medicaid Expansion-No Quick Resolution in Sight. New Engl. J. Med. 2013, 368, 496-499. [CrossRef] [PubMed]

23. Sommers, B.D.; Gruber, J. Federal Funding Insulated State Budgets From Increased Spending Related To Medicaid Expansion. Heal. Aff. 2017, 36, 938-944. [CrossRef]

24. Aaronson, B. Medicaid Dental System an Ongoing Challenge; The Texas Tribune: Austin, TX, USA, 2012. Available online: https:/ / www.texastribune.org/2012/07/27/medicaid-dental-disaster-leaves-children-lurch/ (accessed on 1 August 2021).

25. Avendano, E. Lawmakers Look to Add Dental Coverage for Medicaid Recipients; Honolulu Civil Beat: Honolulu, HI, USA, 2020; Available online: https://www.civilbeat.org/2020/02/lawmakers-look-to-add-dental-coverage-for-medicaid-recipients / (accessed on 1 August 2021).

26. Aday, L.; Begley, C.; Lairson, D.; Slater, C. Evaluating the Healthcare System: Effectiveness, Efficiency, and Equity. Third. Academy Health. 2004. Available online: http:/ /www.getcited.org/pub/100326183 (accessed on 1 August 2021).

27. Mazurenko, O.; Balio, C.P.; Agarwal, R.; Carroll, A.E.; Menachemi, N. The Effects of Medicaid Expansion under the ACA: A Systematic Review. Heal. Aff. 2018, 37, 944-950. [CrossRef]

28. Courtemanche, C.; Marton, J.; Ukert, B.; Yelowitz, A.; Zapata, D. Early Impacts of the Affordable Care Act on Health Insurance Coverage in Medicaid Expansion and Non-Expansion States. J. Policy Anal. Manag. 2016, 36, 178-210. [CrossRef]

29. Buchmueller, T.; Levinson, Z.M.; Levy, H.G.; Wolfe, B. Effect of the Affordable Care Act on Racial and Ethnic Disparities in Health Insurance Coverage. Am. J. Public Heal. 2016, 106, 1416-1421. [CrossRef]

30. Golberstein, E.; Gonzales, G.; Sommers, B.D. California's Early ACA Expansion Increased Coverage and Reduced out-of-Pocket Spending For The State's Low-Income Population. Heal. Aff. 2015, 34, 1688-1694. [CrossRef]

31. McMorrow, S.; Long, S.K.; Kenney, G.M.; Anderson, N. Uninsurance Disparities Have Narrowed For Black And Hispanic Adults Under The Affordable Care Act. Heal. Aff. 2015, 34, 1774-1778. [CrossRef]

32. Moss, H.A.; Havrilesky, L.J.; Chino, J. Insurance coverage among women diagnosed with a gynecologic malignancy before and after implementation of the Affordable Care Act. Gynecol. Oncol. 2017, 146, 457-464. [CrossRef]

33. Sommers, B.D.; Chua, K.-P.; Kenney, G.M.; Long, S.K.; McMorrow, S. California's Early Coverage Expansion under the Affordable Care Act: A County-Level Analysis. Heal. Serv. Res. 2015, 51, 825-845. [CrossRef]

34. Angier, H.; Hoopes, M.; Gold, R.; Bailey, S.R.; Cottrell, E.K.; Heintzman, J.; Marino, M.; DeVoe, J.E. An Early Look at Rates of Uninsured Safety Net Clinic Visits after the Affordable Care Act. Ann. Fam. Med. 2015, 13, 10-16. [CrossRef]

35. Bazzoli, G.J. Effects of Expanded California Health Coverage on Hospitals: Implications for ACA Medicaid Expansions. Heal. Serv. Res. 2015, 51, 1368-1387. [CrossRef] 
36. Berry, S.A.; Fleishman, J.A.; Yehia, B.R.; Cheever, L.W.; Hauck, H.; Korthuis, P.T.; Mathews, W.C.; Keruly, J.; Nijhawan, A.E.; Agwu, A.L.; et al. Healthcare Coverage for HIV Provider Visits Before and After Implementation of the Affordable Care Act. Clin. Infect. Dis. 2016, 63, 387-395. [CrossRef]

37. Breathett, K.; Allen, L.A.; Helmkamp, L.; Colborn, K.; Daugherty, S.L.; Khazanie, P.; Lindrooth, R.; Peterson, P.N. The Affordable Care Act Medicaid Expansion Correlated with Increased Heart Transplant Listings in African-Americans But Not Hispanics or Caucasians. JACC Hear. Fail. 2017, 5, 136-147. [CrossRef]

38. Cole, M.B.; Galarraga, O.; Wilson, I.B.; Wright, B.; Trivedi, A.N. At Federally Funded Health Centers, Medicaid Expansion Was Associated with Improved Quality of Care. Heal. Aff. 2017, 36, 40-48. [CrossRef] [PubMed]

39. Dresden, S.M.; Powell, E.S.; Kang, R.; McHugh, M.; Cooper, A.J.; Feinglass, J. Increased Emergency Department Use in Illinois after Implementation of the Patient Protection and Affordable Care Act. Ann. Emerg. Med. 2017, 69, 172-180. [CrossRef] [PubMed]

40. Nasseh, K.; Vujicic, M. The Impact of Medicaid Reform on Children's Dental Care Utilization in Connecticut, Maryland, and Texas. Heal. Serv. Res. 2015, 50, 1236-1249. [CrossRef]

41. Buchmueller, T.; Orzol, S.; Shore-Sheppard, L.D. The Effect of Medicaid Payment Rates on Access to Dental Care among Children. Am. J. Heal. Econ. 2015, 1, 194-223. [CrossRef]

42. O'Griffin, S.; Barker, L.K.; Wei, L.; Li, C.-H.; Albuquerque, M.S.; Gooch, B.F. Use of dental care and effective preventive services in preventing tooth decay among U.S. Children and adolescents-Medical Expenditure Panel Survey, United States, 2003-2009 and National Health and Nutrition Examination Survey, United States, 2005-2010. MMWR Suppl. 2014, 63, 54.

43. Shadish, W.R.; Cook, T.D.; Campbell, D.T. Experimental and Quasi-Experimental Designs for Generalized Causal Inference; Houghton Mifflin Company: Boston, MA, USA, 2002; pp. 34-102. 